\title{
The constituent pillar of the leadership-elite positioning
}

\author{
Oleg Artyukhin ${ }^{1,2}$, Tatiana Cherkasova $^{2}$, Pavel Colimbet $^{2}$, David Grigoryan ${ }^{2}$, and Anna \\ Kritskaya ${ }^{2, *}$ \\ ${ }^{1}$ Don State Technical University, 1, Gagarin square, 344000, Rostov-on-Don, Russia \\ ${ }^{2}$ South-Russian Institute of Management of Russian Presedential Academy of National Economy and \\ Public Administration, 70/54, Pushkinskaya str., 344002, Rostov-on - don, Russia
}

\begin{abstract}
The purpose of the research is the analysis of the constituent model of leadership and elite positioning and power, identifying the peculiarities of applying this model to modern social and political processes in terms of globalization and informatization. The research methodology was based on the body of scientific methods and approaches in the context of the research subject and logic. An integrative social and psychological approach as well as political analysis were applied. Analysis and synthesis, analogy, generalization, deduction, induction and comprehensive study were applied as the basic methods of the research. The synthesis of structuralfunctional, systemic and institutional approaches resulted in analyzing the constituent approaches to the leadership and elite positioning in the power structures. The article deals with the theoretical and methodological aspects of the leadership subject, analyzes the leadership phenomenon in the current socio-political context, examines the models of cross-elite communication as well as the peculiarities of interaction in the chain: leader- followersconstituents. It is noted in the article, that situational leadership vertical models, which characterize traditional leadership, are limited in the sphere of application. In order to be effective, a leader must make sure there is horizontal communication and feedback between elite, followers and constituents on every level of the power structure. The consolidation of the leader and elite, elite and society should be grounded by common strategic goals and values.
\end{abstract}

\section{Introduction}

The beginning of the 21 st century is characterized by the rapid development and improvement of communicative and information technologies. Large-scale globalization processes have considerably modified the system of public relations, including leadership and management factors.

Therefore, it is of vital importance to identify and systematize the conceptual reasons of transformation of leadership and elite positioning in the power structures. Elite positioning in various types of societies and political systems has got much in common, despite all the differences due to their individual characteristics.

\footnotetext{
*Corresponding author: kritskaya.anna@bk.ru
} 
Under all regimes government endeavors to fortify legitimacy and raise its authority and reputation in the sphere of political communication and informational interaction between public authorities and society. Positioning of the elite in terms of attitude to democracy and interaction with the civil society is determined by the specifics of democratic values perception in different political systems.

Positioning of the elite in the context of attitude to democracy in the countries with the hierarchical structure of distribution of power is attributable to the values shared by the political leader and his inner circle.

When we speak of political elite, we imply a group of individual leaders, which positions itself as the subject of political domineering and leads social development by means of setting socially important goals.

These leaders either by means of seizing the power or taking part in the political struggle with their rivals, and after rising to power, through the use of various methods, political and ideological techniques, strive to position themselves in the power structures and obtain maximum legitimacy. Thus, political elite is a group of people, who possess the instruments of power, it is "the highest stratum of political actors", who exercise socio-political management.

The transition to the informational society during globalization determines a comprehensive change in all the spheres of public relations. The transformation of sociopolitical processes can utterly alter the system of power relations, that is why it is necessary to adopt a new vision of leadership-elite positioning in the context of the theory of constituents in leadership. Consequently, there is a need to reevaluate the interaction of the key actors of modern social and political processes.

Currently, like never before, there is an urgent need to have a leader, capable of implementing strategic goals of the society, consolidating the society, ensuring, due to leadership capital, efficient management and political communication in the chain: leaderelite- followers - constituents.

\section{Methodology and research methods}

On the whole, the given research is based on the integrated socio-political approach, taking into consideration socio-political realities of the modern world order for the purpose of theoretical and methodological modeling of the leadership phenomenon and constituent paradigm. The research involved the use of method of general academic nature, such as analysis and synthesis. Also the study used the principle of comprehensiveness, retrospective analysis, while analyzing some historic realities, etc, as well as the dialectic approach for analyzing the identified contradictions.

The research required using the materials of theoretical sources and statistical data of relevant public opinion polls devoted to the topic of leadership, leadership models, political culture and institutions.

\section{Research Findings}

In modern Russia the leadership factor plays its specific role in the system of distribution of power and political decisions making. The basis of Russian political system is supported by a strong personification of power. Russian system is mostly characterized by its personalist nature rather than institutional one.

One can specify different levels of leadership in accordance with the levels of power and the leader's jurisdiction: nation-wide, regional and local leadership. One should also differentiate between formal, official leaders and the ones, who informally influence the 
political life. The basic typology of leadership depends on the model of power organization and interaction between leaders, followers and constituents, i.e. elite, civil society, electorate in general. It is also important to dwell on the nature of leadership, where it refers to some situational management, or it is the so-called strategic transforming leadership, which means implementing, under the leader's supervision, strategic goals for the society development and high-quality transformation, including moral and ethical transformation.

In 2020 the Swiss University of ST Gallen together with the Russian School of Management Skolkovo and dxFeed Solutions conducted a research of the quality of the elite groups and their influence on various spheres of life ( political, social, economic, etc ) and developed the Elite Quality Index.[1]

Table 1. Elite Quality Index.

\begin{tabular}{|c|c|c|}
\hline Rating & Country & Index \\
\hline 1 & Singapore & 68.5 \\
\hline 2 & Switzerland & 64.9 \\
\hline 3 & Germany & 64.2 \\
\hline 4 & Great Britain & 63.9 \\
\hline 5 & United States of America & 63.4 \\
\hline 23 & $\ldots$ & 48.9 \\
\hline & Russia & \\
\hline 31 & $\ldots$ & 41.6 \\
\hline 32 & Argentina & 40.0 \\
\hline
\end{tabular}

The Elite Quality Index shows the degree of the cumulative influence of national elite groups on the society according to 72 indicators. This index partially reflects the leadershipelite positioning in terms of the constituent approach.

In order to achieve the specified goal let us consider the typology of political leadership. As political research findings show, a state leader's interaction is quite often limited by an inner circle of confidants and some elite circles close to the government. At times, the vertical power structure malfunctions or a gap appears in the cross-elite communication at the level of lower elite circles, which occurs, when at a certain level the vertical stops representing the real interests of the constituents and consequently breaks the connection and interaction on the upper levels.

Thus, in reality a state leader doesn't always express the constituent expectations of the whole society. In this context the so-called horizontal models of cross-elite communication arouse interest most of all in terms of feedback and the opportunity of partnerships between different subjects of political processes. In other words, on a regional and local level a leader can almost directly express the constituent expectations of a certain part of the society.

Leadership-elite positioning and the leader's political influence depend not only on the psychogenetic peculiarities of a certain personality in power, but can also be determined by external and internal factors and consequences of political life at a certain stage of governmental and social development (table 2). The model of leader`s interaction with the rest of the actors of the political processes is a multi-level, complex system. [2] Following the logic, along with the leader's characteristic features, the followers ' characteristics are also of considerable importance, as well as the context of interaction and the way the leader acts under the given circumstances. 
Table 2. Main theories of political leadership.

\begin{tabular}{|l|l|}
\hline \multicolumn{1}{|c|}{ Theory name } & \multicolumn{1}{|c|}{ The essence of the theory } \\
\hline Personality theory & $\begin{array}{l}\text { The nature of leadership is explained by the outstanding } \\
\text { qualities of individuals (intelligence, strong will, } \\
\text { purposefulness, organizational skills, complexity) }\end{array}$ \\
\hline Situational theory & $\begin{array}{l}\text { A leader can appear as a result of a successful combination of a } \\
\text { number of moments - place, time and circumstances, his } \\
\text { personal qualities may often be irrelevant }\end{array}$ \\
\hline Psychological theory & $\begin{array}{l}\text { Leadership is based on an unconscious attraction, which } \\
\text { manifests itself in the desire for power. The leader tries to get } \\
\text { rid of his complexes by imposing his will on other people }\end{array}$ \\
\hline Constituent theory & $\begin{array}{l}\text { It is a continuation of the situational theory, where the leader is } \\
\text { the spokesman for the interests of his followers }\end{array}$ \\
\hline Integrative theory & $\begin{array}{l}\text { Takes into account the main aspects of leadership: analysis of } \\
\text { the leader's personality; its origin; socialization process; ways } \\
\text { of advancement; tasks that he must perform }\end{array}$ \\
\hline
\end{tabular}

Let's analyze in more detail the highlighted elements in the system of implementation of the constituent principle of management, based upon the leader's interaction with elites.

Taking into account a famous typology of socio-political leadership (according to F.Selznik) we should identify institutional and interpersonal types of leadership .

An institutional leader is focused on the protection and implementation of goals and objectives put forward by a particular institution, administration or a group in front of group members. This is considered to be the purpose of his political management. Such a leader is committed to formal principles and regulations and demands of his subordinates to follow them strictly.

An interpersonal leader is more focused on an interpersonal factor, which means he is more interactive, communicates with people in order to build a team, that will be based on loyalty, ability to resolve interpersonal contradictions and conflicts, determination to reduce tension and anxiety within the group .

According to R. Bales' typology, there are two types of leaders - "business" and "popular". A business leader is focused on a definite goal, an objective, and using all available means, he/she tries to make the group members achieve it. Whereas a popular leader uses his/her influence mechanisms on the interpersonal level of interaction, actively attracts informal relations and contacts.

As a rule, according to M. Hofstetter, the types of leaders described above coexist within a certain group and can manage the group simultaneously, from time to time either of them dominates, helps or interferes with the other one [3].

From the procedural point of view, according to U. Hemfill, leadership can be classified into experimental, successful, and efficient, which is also determined by the leader's way of influencing the group members, the process and result achieved by the group.

Thus, generally speaking, the ability to influence the supporters and subordinates so that they follow and share the leader's values /goals, approve and execute his/her tactic -strategic political decisions and trust his/her authority remains the topical goal of the leader. [4]

As is well known, the concept of a leader and leadership is considered at least in two directions.

The first is connected with certain qualities and background of a person, due to which he / she occupies the leading position in the group, becomes a formal or informal leader. One can say, that being a leader is a personality characteristic. And the approach, on the whole, can be seen as psychological. [5]

The second vector of interpretation of a leader and leadership concept is connected with the idea of management and administration, that is why in this case the emphasis is put on the leader`s position in the system of management and power and he/she is analyzed primarily 
as a manager in an organization or a group. Basically, such an approach is called social.

Obviously, these two approaches are interconnected and interdependent, and the person, who becomes a leader tends to have certain background and qualities, which explain his /her determination to hold leading positions, senior roles, etc. At the same time, a manager can be appointed to the position due to some reason, not connected with his personal characteristics, but because of some family relations, nepotism, his/her devotion to superior management, etc. [6]

In such a case a leader is not a person possessing leader`s qualities, but, to some extent, a victim of circumstances. A reverse situation can also occur, when a person, who has the necessary qualities of a leader, becomes an outcast in the society, a marginal person, which pushes him far from the system of management and participation in politics. [7]

Therefore, the leadership concept should include both the leader's positioning in the system of social connections and political relations (political position, political power, post, administrative resource, political capital, confidents, electorate, etc) and the perception (selfperception) of this person as a leader, and in this case such elements as charisma, natural inclination to dominance, etc are taken into account. [8]

As for political leadership, the political leader is a leader, who, in addition to his/her special position in the system of socio-economic and political relations, has socio-political charisma, political vision and the ability to consolidate around him/herself the elite and society through tactic and strategic goals for the development of society. [9]

So, in order to be efficient, a political leader needs to possess the necessary resources of power on the structural and functional level, identity capital (some outstanding personal qualities and charisma ) as well as a high level of trust among his followers, constituents, etc.

The term "follower" is interpreted in a similar way, because a follower is not only a person, who follows the leader, shares his/her political views, goals and values. A follower is also a subordinate, that is a person taking an inferior position in relation to a higher -ranking person in the socio-psychological system.

Bearing in mind the fact, that the term "follower" is widely interpreted in the English language and can be considered as both a supporter and a subordinate, one should use the term "constituents" in a broader meaning. This term was introduced to the theory of leadership by F. Stanford and one should take into consideration the chain: leader -activistsfollowers- constituents. [10] It is the constituents and followers, who mostly determine the position of their leader, who the leadership-elite positioning depends upon. From the theoretical and methodological point of view the theory of leadership constituents (the theory of followers) is the evolution of the concept of situational leadership, but in modern times it is gaining its specific features and peculiarities.

\section{Discussion}

While achieving the goal of the research we conducted a political analysis of the constitutional model in the leadership-elite positioning and influence and identified the peculiarities of applying this model to the current socio-political processes in the context of globalization and informatization.

It should be noted, that there is an objective trend of shifting socio-political and sociopsychological researches from the leader onto his relations with the followers, that means shifting form leadership-centric approach towards the analysis of constituent models and connections. Let's observe some of the factors, which influence the development of this trend:

Firstly, this is the result of increased specialization and professionalization of political activity, where a politician is not only the Grand Chief of the people in the traditional form, 
but it is a professional, able to efficiently solve socio-political tasks of the state and society. [11]

Secondly, this can be objectively explained by the end of the traditional family on a global scale (single parent, both parents have equal rights, both parents work and so on) and the erosion of traditional values, when the traditional authority and leadership lose their sociopsychological legitimacy and decline in relevance.

Thirdly, due to the information era we live in, the development of social media and communication technologies, the authorities and the political leader have stopped being the only information providers and owners. Paradoxically, but the leader's opportunities to influence and control the society have increased and declined at the same time. On one hand, there has been a considerable increase of the leader's capability to spread the information and at the same time to let the followers be aware of their leader's political point of view. On the other hand, it has become much more difficult for the leader to present his point of view as the only right one and the only possible.

Fourthly, a sequence of current financial and socio-cultural crises undermines the public confidence in political authorities, and political leaders are quite rapidly losing their political credibility and capital.

Finally, due to the modern political technologies it has become possible to introduce new political players on the political arena, consequently, the leader can overnight lose his supporters and followers. A modern political leader should not only give top-down orders and develop political initiatives, but also meet his followers' social and psychological needs and expectations. It is essential to not only to be a good speechmaker, but be able to listen, understand, find compromise solutions to conflicts.

A peculiar feature of modern followers of the leader is that, as a rule, they are mobile, active, professional people, who pursue their career, aspire for success and personal growth (and they are focused on the results they can have now, not in the long-term perspective), they are informed and knowledgeable in different spheres and they are active users of social media and internet. In other words, they are active and interactive followers, who learn fast and change the patterns of interaction between all the actors and agents of the socio-political arena. [12]

However, if we take into consideration the intensity of color revolutions, maydans, and public rebellions in our modern times, one should draw a conclusion, that the people, the crowds also play an important role and can be seen as followers, who have a significant influence on their leader. [13]

To put it another way, the issue of leadership and the analysis of leadership model can not be studied in separation from the major determining factors of socio-political life [14], cultural and historic context and the personality of the leader. When choosing an adequate model of leader's interaction with followers and constituents the political culture of the society plays a substantial part. And also of crucial importance is the potential opportunity to form many-sided forward and backward connections in the chain leader-followersconstituents [15], with the help of which not only the leader can have influence on the life of his electors [16], but the electors have the opportunity to monitor the activity of the proposed leader both during elections and in the process of his fulfillment of the election promises.

Thus, leadership implies not only a charismatic person in power, but also the system of leader's interaction with followers-group members, and in a broader sense with elite and the society.

It has become quite obvious, that both on the level of business and on the level of political process and institution efficient and successful management cannot be achieved by using authoritative means only. The vertical models, where there is just one captain giving administrative orders, are no longer efficient in the contemporary world. 


\section{Conclusions}

In the modern concepts of leadership and elite positioning one can notice a shift from leadercentrism, which means that it is the leader's personal characteristics and leadership model determine the major outcomes of socio-political events, and a new emphasis is put on studying the system of interaction in the chain leader- followers-constituents, in which nonlinear connections and reverse cycle of influence take place, which results in the transformation of the leader, followers and socio-political system as a whole. Therefore, the use of the constituent approaches to the phenomenon of leadership provides a comprehensive view of the interactions and relations in the leader-followers-constituents system. It is important, that the followers may have influence on their leader's authority, building on charismatic, emotional, irrational and rational grounds. Since the followers are people with different levels of socio-political competence and maturity, the political leader needs to be able to change his/her style of interaction with the followers in accordance with the situation, maintaining the balance between tactic and technical and strategic tasks, between emotional and rational motives

This rejection of the leader-centric approach results in the increase of the importance of situational, attributive interpretations of leadership. Attributive approaches take into account the dynamics of leadership-elite interaction within the leader-followers-constituents system, they emphasize the interest to studying the backward connections, when not only the leader, but his followers and constituents as well influence the management cycles and decision making at every stage and level of exercising power.

Consequently, one should thoroughly consider the constituent principle of leader's interaction with elite and followers, which demonstrates that the political leadership phenomenon is closely related to attributive characteristics of the leader's followers, who ensure his/her political power and are capable of reverse influence and control of his/her political activity.

\section{References}

1. Elite Quality Report 2020: 32 Country Scores and Global Rank, https://www.alexandria.unisg.ch/260885/1/Elite_Report.pdf., last accessed 2021/03/11.

2. Pratch, L., Jacobowitz, J.: The Psychology of Leadership in Rapidly Changing Conditions A Structural Psychological Approach. Genetic Social and General Psychology Monographs 123(2),169-196 (1997)

3. Kirilenko, V., Alekseev, G. Modern Democracy and Political Leaders. Administrative Consulting 1(7):17-31. (2018) doi:10.22394/1726-1139-2018-7-17-31

4. Garita, M.: A Sociological Approach Concerning Leadership: How CEO and the Masses Behave. Nile Journal of Business and Economics 2(3), 15-24 (2016),15 doi:10.20321/nilejbe.v2i3.63

5. Lyubashits, V., Mamychev, A., Uvarova, G., Artyukhin, O., Chapurko, T.: Sociocultural measurement of institutional and functional characteristics of public-power interactions. Man in India. 97 (23), 461-470. (2017) doi: 10.7596/taksad.v7i3.1748

6. Mamychev, A.Yu., Okhotsky, E.V., Frolov, S.S., Ponedelkov, A.V., Vorontsov, S.A.: Statement and implementation of goals of the political strategy is the basis of effective public administration. Revista Inclusiones 6, 475-486. (2019)

7. Taherdoost, H., Madanchian, M.: Prioritization of Leadership Effectiveness Dimensions Improving Organizational Performance via Analytical Hierarchy Process (AHP) Technique: A Case Study for Malaysia's Digital Service SMEs. Digital Transformation 
and Innovative Services for Business and Learning, 1, 21 (2020) doi: 10.4018/978-17998-5175-2.ch001

8. Grove, R.C., Terrell, H.K.: Political Leadership. Encyclopedia of Personality and Individual Differences. Springer, Cham, 6, 51-76 (2018) doi: 10.1007/978-3-319-280998_1805-1

9. Oyinlade, A.O.: A Method of Assessing Leadership Effectiveness. Performance Improvement Quarterly 19(1):25 - 40 (2008) doi: 10.1111/j.1937-8327.2006.tb00355.x

10. Stewart S.: Fundamental Attitudes of the Russian Political Elite (Law, Truth, Public Welfare and Violence). SWP Research Paper Stiftung Wissenschaft und Politik German Institute for International and Security Affairs. Berlin, 33 (2017)

11. Ponedelkov A.V., Starostin A.M., Verenich I.V., Mamychev A.Yu., Grigoryan D.K.: Leader and elite positioning in hierarchical system of power distribution: Russian option. Revista San Gregorio. 25, 170-177 (2018)

12. Garita M.: A Sociological Approach Concerning Leadership: How CEO and the Masses Behave. Nile Journal of Business and Economics 2(3):15 (2016) doi: 10.20321/nilejbe.v2i3.63

13. Avdokushin E., Ponedelkov A., Vorontsov S. The Role of Russian Federal and Regional Political Elites in the Modernization of Public Administration. Slavica Publishers, 2 (4), 327-346 (2015)

14. Ponedelkov, A. V., Starostin, A. M.: Modern Russian elite representation in expert measurement. - Communicology. 1, 61-68 (2016)

15. Hazin, S.: Goldfinches of Page. A ladder into the sky. Dialogues about the power, career and world elite. Moscow, Kipolklassik, 624 (2016)

16. Ponedelkov, A. V., Starostin: Leader and elite projection of political processes of modern Russia: results of researches of the last 20 anniversary (1994-2014). Rostov N/D.: YRIU RANEPA publishing house. 112. (2015) 